\title{
Effect of fiber volume fraction in the tensile properties of renewable Diss fiber /polyester composite
}

\author{
Bouakba Mustapha*, Issasfa Bahim, Boukatem Mourad and Belloufi Abderrahim
}

Département de Génie Mécanique, Faculté des Sciences Appliquées Université Kasdi Merbah Ouargla, 30000 Algérie

\begin{tabular}{|c|c|}
\hline $\begin{array}{l}\text { ARTICLE INGO } \\
\end{array}$ & A B S T RAC T \\
\hline $\begin{array}{l}\text { Article history: } \\
\text { Received } 6 \text { April, } 2015 \\
\text { Accepted } 24 \text { November } 2015 \\
\text { Available online } \\
\text { 25 November } 2015 \\
\text { Keywords: } \\
\text { Renewable fibers } \\
\text { Diss } \\
\text { Ampelodesma mauritanica } \\
\text { Natural fibers } \\
\text { Composite } \\
\text { Tensile nronerties }\end{array}$ & $\begin{array}{l}\text { This paper presents a novel composite material produced by a natural reinforcement subjected } \\
\text { to tensile test. The used reinforcement is made of Diss fibers. The Diss (Ampelodesma } \\
\text { mauritanica) is a Mediterranean wild plant. This fiber is characterized in tensile according to } \\
\text { ASTM standard. The results obtained show that the fiber Young's modulus and the stress at } \\
\text { break were very interesting and were similar to those obtained for some natural fibers such as } \\
\text { sisal fiber. The composite was developed to study by three differing volume fractions of } 20 \% \text {, } \\
30 \% \text { and } 40 \% \text {. }\end{array}$ \\
\hline
\end{tabular}

\section{Introduction}

In the recent years, many researchers took the challenges to replace the synthetic fibers by the renewable fibers in composite materials. Natural fibers have many advantages like good mechanical properties, lower density, and environmental impact (Bouakba et al., 2013; Ben Brahim \& Ben Cheikh, 2007). The main advantages to use natural fibers in composite are: low cost, low weight, biodegradable, ecological, and renewable. However, two major reasons limit applying natural fibers reinforced composite. First, the tensile strength of natural fiber is very low compared to Synthetic fibers. The second is the water absorption (Wambua et al., 2003). Although synthetic fibers such as glass fibers, have been used frequently in the past for reinforcing different types of composites (Alhozaimy et al., 1996; Tobbi et al., 2012; Almusallam et al., 2012; Aliha et al., 2012; Yao et al., 2013; Mazaheripour et al., 2013; Mohamed et al., 2013; Heidari-Rarani et al., 2014; Adam et al., 2015; Paul, 2003), to the best of the authors' knowledge, no previous attempt has been performed at manufacturing fibers for plastic reinforcement from the Diss plants. This work aimed to use the Diss fiber in strengthening of composite material. The Diss (Ampelodesma mauritanica) is a wild plant, very fibrous over large parts of

* Corresponding author.

E-mail addresses: bouakba.mu@gmai.com, bouakba.mu@univ-ouargla.dz (B. Mustapha) 
Mediterranean countries. In the present work, we investigated the tensile properties of the Diss fiber and the composite fabricated by a molding process. Two parameter Weibull distributions have been used to carry out statistical analysis on fiber strength and Young's modulus.

\section{Experimental Method}

The studied composite material is made of a polyester matrix reinforced with Diss fibers. Table 1 gives these properties of the used matrix.

Table 1. Polyester unsaturated resin properties

\begin{tabular}{lcc}
\hline Properties & Value & Unit \\
\hline Density & 1.2 & $\mathrm{~g} / \mathrm{cm}^{3}$ \\
Young's modulus & 500 & $\mathrm{MPa}$ \\
Tensile stress at failure & 30 & $\mathrm{MPa}$ \\
Tensile strain at failure & 2.5 & $\%$ \\
\hline
\end{tabular}

The composite plates have been fabricated using a molding technique at low pressure equal to 3 Bars, with impregnation at room temperature $\left(18\right.$ to $\left.20^{\circ} \mathrm{C}\right)$. The unsaturated polyester resin has been hardened and catalyzed in percentage between 0.5 and $1 \%$ in mass. After the matrix polymerization, structural composite plates are obtained with the dimension $400 \times 400 \times 2$, and having a different fiber's volume fraction $20 \%, 30 \%$ and $40 \%$. The fiber volume fraction is affected by the geometric parameters of fiber arrangement within the fibrous structure, their orientation, and the spacing between fibers (El Messiry 2013). In this work the fiber volume fraction for these plates composites elaborated has been calculated according to ASTM D2854 standard as:

$$
V_{f}=\left[\rho_{m} \times \frac{W_{f}}{\rho_{m} \times W_{f}+\rho_{f} \times W_{m}}\right] \text {, }
$$

where $\rho_{m}$ is density of matrix, $\rho_{f}$ is density of fibers, $W_{m}$ is weight of matrix and $W_{f}$ is weight of fibers.

\subsection{Density of Diss-fiber Measurements}

The density of these fibers is carried out by the Pycnometer method for five specimens at a room temperature. The mean value of this density is equal to $0.85 \mathrm{~g} / \mathrm{cm}^{3}$. This result is a very interesting compare to other natural fibers. For example the density of the sisal fiber is equal to $1.2 \mathrm{~g} / \mathrm{cm}^{3}$, and the density of glass fiber is equal to $2.4 \mathrm{~g} / \mathrm{cm}^{3}$. The use of Diss fibers in reinforced plastic fiber can save in one $\mathrm{m}^{3}$ a weight equal to $350 \mathrm{Kg}$ from the sisal fibers, and save a weight equal to $1550 \mathrm{Kg}$ from the glass fibers. From another point of view we can economize about $30 \%$ and $64.58 \%$ of the cost compared to the price, which cost him, the use of sisal fibers and glass fibers respectively.

\subsection{Fibers and Composite Tensile}

A total of 50 fibers was tested at a room temperature with a fiber length of $250 \mathrm{~mm}$. The tensile properties of the Diss fibers are determined experimentally according to ASTM standard D3039. The experiments are carried out with a single column ET traction machine equipped with a $10 \mathrm{KN}$ load cell, with a velocity equal to $15 \mathrm{~mm} / \mathrm{min}$ in order to get a total time test of $20 \pm 3 \mathrm{~s}$. During the axial loading, the short fiber appears the high scatter behavior. The behavior makes the analysis of results difficult (Belaadi et al., 2014). In order to avoid this difficulty our fiber tests have a length equal to $250 \mathrm{~mm}$. The studied composite plates with a two different volume fractions and two fibers length mentioned above have been subjected to axial loading according to the ASTM D3039 standard, with a constant speed of $2 \mathrm{~mm} / \mathrm{min}$. The test specimens have a length of $250 \mathrm{~mm}$, a width of $25 \mathrm{~mm}$ and a thickness of $2 \mathrm{~mm}$. five specimens have been tested for each volume fraction and for each fiber length. 


\subsection{Statistical analysis with Weibull distribution}

The following equation show the Weibull distribution with two parameters, which has been used to determine the dispersion of the tensile strength and the Young's modulus:

$$
\mathrm{P}(\sigma)=1-\exp \left\{-\left(\frac{\sigma}{\sigma_{0}}\right)^{\mathrm{m}}\right\}, \quad \sigma>0, \quad \sigma_{0}>0, \quad m
$$

where $\mathrm{P}(\sigma)$ is the probability of survival of the parameter $\sigma, m$ is a shape parameter or the Weibull modulus related to the dispersion of the data and $\sigma_{0}$ is an average value of $\sigma$ (Belaadi et al., 2014). The probability of failure value for each strength was defined as:

$$
\mathrm{P}=\frac{\mathrm{i}-1}{\mathrm{n}}
$$

where:

$i=1,2,3, \ldots, n$

$n=$ total number of specimens tested.

In order to define the average value of Young's modulus and tensile strength it is necessary to follow these steps:

Step 1: For each strength calculate

$$
\mathrm{Y}_{\mathrm{p}}=\ln \{\ln [1 /((1-\mathrm{P})]\}
$$

Step 2: Plot the calculated $Y_{P}$ vs. $\ln \sigma$

Step 3: Use a linear least-squares method to fit a straight line to the data. The slope of this line is equal to $m$, and its intersection with the $\ln \sigma$ axis is equal to $\ln \sigma_{0}$.

\section{Results and Discussion}

The typical Load-Displacement curve for a Diss fiber is shown in Fig. 1. The Diss fiber subjected to tensile load has a similar behavior when compared to other natural fibers shown in the open literature. The Young's modulus of the Diss fiber is calculated by:

$$
\mathrm{E}=\frac{\sigma}{\varepsilon}
$$

where $\varepsilon$ is the strain calculated by $\varepsilon=\frac{\mathrm{u}}{\mathrm{L}}$, with $\mathrm{u}:$ represent the displacement of the crosshead, and $L$ is the length of the fiber. The stress is calculated as:

$$
\sigma=\frac{F}{S}
$$

where $F$ is the load; and $S$ is the cross section of these fiber used in this study.

Table 2 illustrates the average value of the tensile properties of the Diss fibers obtained by the two parameters Wiebull distribution. The tensile modulus and strain at failure and stress at failure for this 
Diss fiber shown similar values when compared to sisal fiber presented in literature (Belaadi et al., 2014).

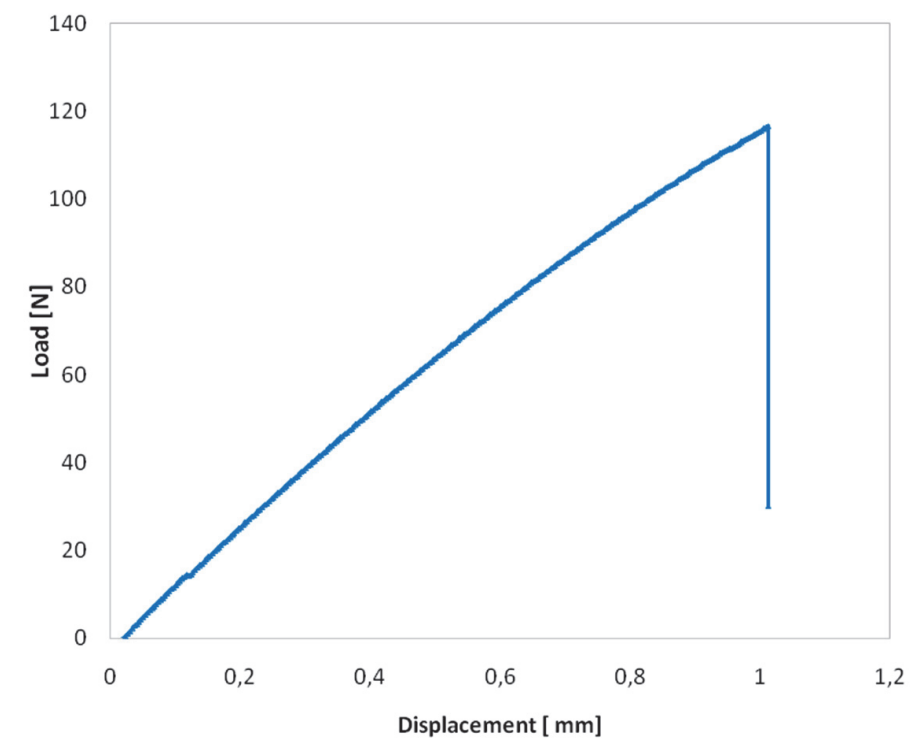

Fig. 1. Typical Load-Displacement curve for a Diss fiber

Table 2. Tensile properties of the Diss fiber

\begin{tabular}{cccc}
\hline Tensile properties & Average value & Variation ratio $(\%)$ & Confidence interval at 93\% \\
\hline Young Modulus $(\mathrm{GPa})$ & 8.5 & 28.5 & {$[7.5: 10.5]$} \\
Stress at failure $(\mathrm{MPa})$ & 105 & 30 & {$[80: 115]$} \\
Strain at failure $(\%)$ & 2 & 32 & {$[1.8: 2.65]$} \\
\hline
\end{tabular}

Fig. 2 and Fig. 3 show the average results from the axial load measurements carried out on a series of five composite samples for each fiber volume fraction $\left(V_{f}\right)$. The average value of the tensile strength and the tensile modulus for the $V_{f}$ equal to $30 \%$, is around $102 \mathrm{MPa}$ and $3.5 \mathrm{GPa}$, with a standard deviation corresponding respectively to $2.7 \%$ and $5 \%$ of the mean value. The tensile strength for these Diss fibers reinforced composites with a $V_{f}$ equal to $30 \%$ is 1.30 times higher than the one measured from the composite plates has a $V_{f}$ equal to $20 \%$, and 1.27 times higher than the one measured from the composite plates have a $V_{f}$ equal to $40 \%$.

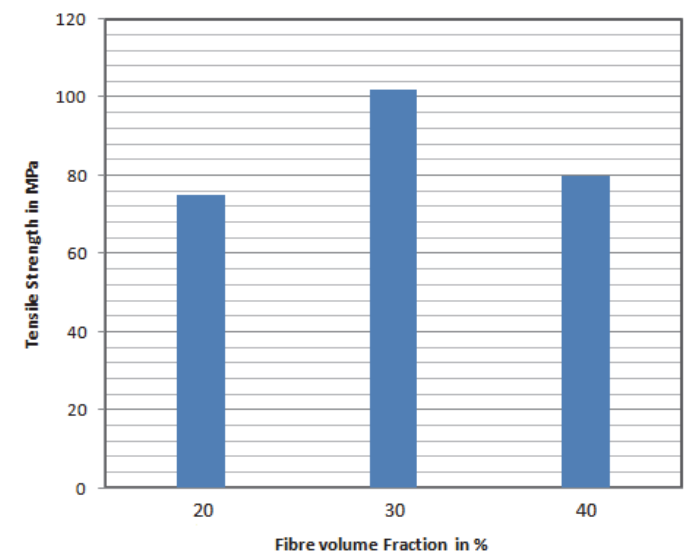

Fig. 2. Effect of fiber volume fraction on the tensile strength for the Diss / Fiber Reinforced composite

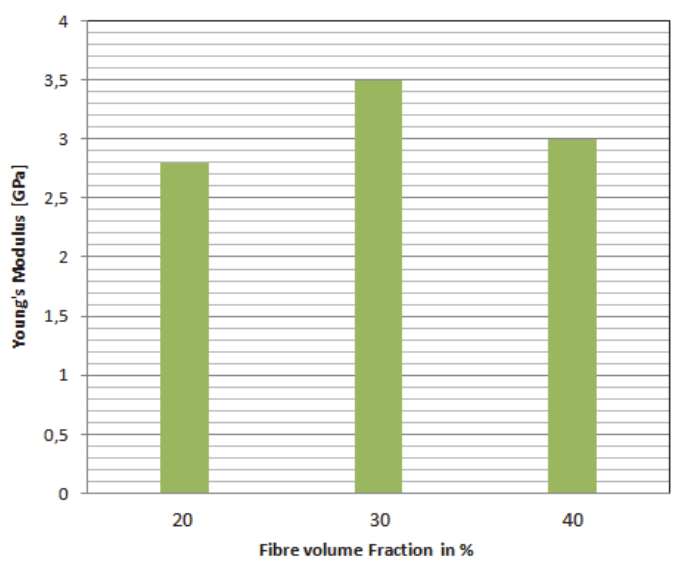

Fig. 3. Effect of fiber volume fraction on the Young Modulus for the Diss / Fiber Reinforced composite 


\section{Conclusion}

The Diss fiber and composites evaluated in this paper demonstrate the following characteristics:

The Diss fiber has an excellent property and a similar behavior compared to other fiber shown in open literature.

1- The tensile modulus, strain at failure and stress at failure for this Diss fiber have shown similar values when compared to sisal fiber presented in the open literature.

2- The composite elaborated have a $V_{f}$ equal to $30 \%$ shows the highest tensile strength and tensile modulus compared to the other prepared by the $V_{f}$ equal to $40 \%$ and $20 \%$.

3- The use of the natural fiber causes to low price, low weight, biodegradable ecological, and renewable.

\section{Acknowledgement}

The authors would like to thank the anonymous referees for constructive comments on earlier version of this paper.

\section{References}

Adam, M. A., Said, M., Mahmoud, A. A., \& Shanour, A. S. (2015). Analytical and experimental flexural behavior of concrete beams reinforced with glass fiber reinforced polymers bars. Construction and Building Materials, 84, 354-366.

Alhozaimy, A. M., Soroushian, P., \& Mirza, F. (1996). Mechanical properties of polypropylene fiber reinforced concrete and the effects of pozzolanic materials. Cement and Concrete Composites, $18(2), 85-92$.

Aliha, M. R. M., Heidari-Rarani, M., Shokrieh, M. M., \& Ayatollahi, M. R. (2012). Experimental determination of tensile strength and K (IC) of polymer concretes using semi-circular bend(SCB) specimens. Structural Engineering and Mechanics, 43(6), 823-833.

Almusallam, T. H., Al-Salloum, Y. A., Alsayed, S. H., El-Gamal, S., \& Aqel, M. (2012). Tensile properties of glass fiber-reinforced polymer bars embedded in concrete under severe laboratory and field environmental conditions. Journal of Composite Materials, 0021998312440473.

Belaadi, A., Bezazi, A., Bourchak, M., Scarpa, F., \& Zhu, C. (2014). Thermochemical and statistical mechanical properties of natural sisal fibres. Composites Part B: Engineering, 67, 481-489.

Bouakba, M., Bezazi, A., Boba, K., Scarpa, F., \& Bellamy, S. (2013). Cactus fiber/polyester composite: Manufacturing, quasi-static mechanical and fatigue characterization. Composites Science and Technology, 74, 150-159.

Brahim, S. B., \& Cheikh, R. B. (2007). Influence of fibre orientation and volume fraction on the tensile properties of unidirectional Alfa-polyester composite. Composites Science and Technology, 67(1), 140-147.

El Messiry, M. (2013). Theoretical analysis of natural fiber volume fraction of reinforced composites. Alexandria Engineering Journal, 52(3), 301-306.

Heidari-Rarani, M., Aliha, M. R. M., Shokrieh, M. M., \& Ayatollahi, M. R. (2014). Mechanical durability of an optimized polymer concrete under various thermal cyclic loadings-An experimental study. Construction and Building Materials, 64, 308-315. 
Mazaheripour, H., Barros, J. A., Sena-Cruz, J. M., Pepe, M., \& Martinelli, E. (2013). Experimental study on bond performance of GFRP bars in self-compacting steel fiber reinforced concrete. Composite Structures, 95, 202-212.

Mohamed, N., Farghaly, A. S., Benmokrane, B., \& Neale, K. W. (2013). Experimental investigation of concrete shear walls reinforced with glass fiber-reinforced bars under lateral cyclic loading. Journal of Composites for Construction.

Paul, W., Jan, I., \& Ignaas, V. (2003). Natural fibers: can they replace glass in fiber reinforced plastics. Compos. Sci. Technol, 63, 1259-1264.

Tobbi, H., Farghaly, A. S., \& Benmokrane, B. (2012). Concrete columns reinforced longitudinally and transversally with glass fiber-reinforced polymer bars. ACI Structural Journal, 109(4).

Yao, W., Li, J., \& Wu, K. (2003). Mechanical properties of hybrid fiber-reinforced concrete at low fiber volume fraction. Cement and concrete research, 33(1), 27-30. 